\title{
Mindfulness: Awareness Informed by an Embodied Ethic
}

\author{
P. Grossman
}

Published online: 19 December 2014

(C) Springer Science+Business Media New York 2014

\section{Introduction}

Within just the last decade, the word mindfulness has gained enormous popularity and traction in Western society, commerce and science. Long in vernacular English usage to define "the quality or state of being conscious or aware of something (Oxford Online Dictionary [http://www.oxforddictionaries. com])," or "the state or quality of being mindful; attention; memory (obs.); intention, purpose (obs.)" from 1530 A.D. (from the Oxford English Dictionary [www.oed.com]), a specialized meaning of the word was, perhaps, first offered to academic psychology about 35 years ago as (1) "the ability to view both objects and situation from multiple perspectives and (2) the ability to shift perspectives depending upon context" (Langer and Newman, 1979).

The current broad enthusiasm for mindfulness, nevertheless, seems mainly to derive from a philosophical, psychological, and religious, semantic amalgam, recently flown onto Western mainstream shores and adapted from a far continent of Buddhist beliefs, knowledge, and understanding. The Oxford Online Dictionary defines this kind of mindfulness as "a mental state achieved by focusing one's awareness on the present moment, while calmly acknowledging and accepting one's feelings, thoughts, and bodily sensations, used as a therapeutic technique (http://www.oxforddictionaries.com)."

Given the diversity of origins and often lack of familiarity with non-Western, Buddhist concepts in which mindfulness is embedded and constituted, it should not be surprising that definitions and applications continue to expand toward varieties of meaning only sometimes even partially overlapping with each other (Grossman, 2011). This has led to a number of

P. Grossman $(\bowtie)$

Department of Psychosomatic Medicine, University Hospital Basel, Hebelstrasse 2, CH-4031 Basel, Switzerland

e-mail: paul.grossman@usb.ch concerns regarding comparability of mindfulness practices in different clinically relevant programs, issues of how and whether to attempt to quantify mindfulness, conflation of Buddhist and Western psychological and popularized notions of mindfulness, and concerns that mindfulness become denatured to an extent that the practice loses its innovative, radical meaning and becomes just another word for attention (e.g., Grossman, 2011; Grossman and Van Dam, 2011). Additionally, there is growing discussion about how varying cultural, religious, social, and linguistic contexts may color fundamental Buddhist constructs of mindfulness practices, even as they are attempted faithfully to be adapted in the West (Germano, 2014).

In this paper, I restrict my discussion to mindfulness as defined within Buddhist thought that has entered Western meditation practices, psychology, medicine, and science. As a response to the heavily cognitive, clinical, and neuroscience orientations toward mindfulness, I emphasize here the ethical dimensions in which mindfulness plays a central role in every Buddhist tradition, whether Theravadin, Tibetan, or Zen. Monteiro et al. (2015) have discussed ethics as a foundational element of mindfulness practice (in Buddhism) and indicated the potential importance of explicitly incorporating ethical considerations into mindfulness programs and interventions in science, medicine, psychology, education, and commerce. Here, I would like to advance the thesis that an important aspect of discussion has been neglected: Although many interwoven skeins are involved in its definition, mindfulness, within the broader, contextualized Buddhist framework, also constitutes an embodied ethical act, process, and practice.

Ethics is meant and defined here, not as part of a system of religious imperatives, but, more generally, in terms of a coherent set of "values relating to human conduct, with respect to rightness and wrongness of certain actions and to the goodness and badness of the motives and ends of such actions (Stanford Encyclopedia of Philosophy, online definition; 
http://plato.stanford.edu/)." A brief further discussion of the meaning of "ethical stance" and what distinguishes "right" from wrong will appear later. Suffice it here to say, we are not talking about a set of rules based upon theistic obligations or duties, but rather the development of an internal and literally embodied set of attitudes and values, derived from the practice of intentionally turning toward immediate experience in a very special way.

I hope to explain how cultivation of mindfulness is inherently oriented toward development of an ethical stance toward the self, others, and all animate and inanimate objects in the world and universe. I also need to state my belief that a parochial parsing of definitions of mindfulness among Buddhist traditions (which do vary somewhat) may be unimportant, unhelpful, and even a source of confusion and false license for psychologists to define the word any way they see fit (i.e., if the different branches of Buddhism cannot agree about what mindfulness is, why should we psychologists agree to a specific definition?). The word mindfulness, itself, only has full meaning when it is embedded in a system of practices and conduct that is essentially shared among the major Buddhist traditions (cf. Goldstein 2002).

To begin, it may be helpful to unpack and even consider a slight altering of the current major definition of mindfulness, as adapted from Buddhist meanings. A relatively standard definition, as quoted above from the Oxford Online Dictionary, depicts our general Western understanding of the Buddhist construct: "a mental state achieved by focusing one's awareness on the present moment, while calmly acknowledging and accepting one's feelings, thoughts, and bodily sensations ...."

This definition explicitly characterizes mindful as a mental state (not a disposition or trait) achieved by a process having met at least four necessary conditions: intentionality, focus on the present moment, awareness derived from that attentional focus (whether awareness of bodily sensations, affect, or thoughts), and a stance of acceptance toward whatever has arisen into awareness as a consequence of the attentional focus. The first two attributes would seem very similar or identical to common definitions of attention as "concentration of awareness on some phenomenon to the exclusion of other stimuli" (Encyclopedia Britannica). They pertain to all forms of attentional activity, from attending to a lecture, to listening to music, to playing video games. Alone, these activities do not necessarily characterize acts of mindfulness. For mindfulness, in the Buddhist sense, to be present, a special kind of awareness is required in which that awareness is continuously conditioned by equanimity (essentially composure of mental and emotional functioning) and acceptance of the stream of perceived experiences that spontaneously arise. In this state, the usual analysis, judgment, evaluation, and even rumination associated with conscious mental acts are supplanted by attitudes of patience, openness, lack of prejudice, tolerance, and kindness to what has arisen, often summarized in the literature by the words "acceptance" and "non-judgment." The centrality, complexity, and challenges to developing and maintaining these qualities are commonly lost to discussion and, in my opinion, trivialized in the psychological literature. Mindfulness becomes primarily moment-to-moment attention to perceptible experience - with acceptance, perhaps, a necessary accessory, but one considered so easily achieved that it warrants little comment.

I should, therefore, like to somewhat reverse the emphasis and offer one definition of mindfulness as an "act of unbiased, openhearted, equanimous experience of perceptible events and processes as they unfold from moment to moment (i.e., sensations, perceptions, thoughts [including memories], emotions, imagery, as well as any other mental context we may be aware of at any moment)." This definition alters the prominence of primarily attentional phenomena for mindfulness in the direction of an act whereby attention and a particular set of attitudes coalesce to achieve a special state called mindfulness. To paraphrase (Olendzki 2011, p. 61): 'The factors that co-arise with mindfulness under all circumstances also help define it and refine how it functions in the mind. Generosity (alobha, from the Pali) and kindness (adosa) help clarify that mindful attention neither favors nor opposes the object, but rather expresses the quality of equanimity. This is where modern definitions of mindfulness get the sense of not judging the object but of accepting it just as it is.'

\section{Ethical Conduct in Buddhist Practice}

Buddhist thought and approaches to ethical conduct and virtue constitute a very clear system, but one not primarily based upon prescriptive or proscriptive rules decreed from higher moral authorities. Rather, the Buddhist ethic is immersed in and emerges from considering the simple experience of being alive in the world: actions and thoughts meant to cause harm are considered unwholesome; whereas conduct and mental activity meant to be benevolent or helpful are, on the other hand, considered wholesome. This is the fundamental basis of Buddhist ethics. Nested within this simple distinction, there are, of course, many more subtle and significant factors that I am not prepared to treat here (e.g., What is the precise definition of harm? Is it wholesome or unwholesome to harm someone who is an imminent danger to innocent others? When may behavior be considered intentional and when not?). Nevertheless, there is an enormous range of unwholesome behaviors and activities that can easily and clearly be distinguished in daily life: lying and stealing or intentionally inflicting psychological or physical injury upon a person. These acts not only create suffering for the victims but also typically for the perpetrator. Likewise, it is easy to come up with clear examples of wholesome conduct from everyday experiences: helping 
someone in need, being generous to another, and speaking kind, honest words of communication. These latter actions typically result in a feeling of amity and wellbeing both for doer and beneficiary. Within this broad perspective, such wholesome conduct, applied to the range of ever-changing circumstances of existence, provides an affirmation of life itself, a turning toward all experience in a benevolent manner, trying to avoid harm, as best we can, but fully open to the richness and poignancy of those aspects of life we cannot control or avoid. Unwholesome behavior and thoughts that cause harm, on the other hand, are acts of denial, fictions that turn us away from the realities of life and change. They, by definition, cause damage and are often motivated by attempts either to become overly attached to pleasant experience or to avoid or repress unavoidably occurring unpleasant experiences, without the awareness of the impermanence of all events and processes, and without awareness of our own limited ability for control.

The root attitudes of unwholesomeness in Buddhist thought are greed, aversion, and delusion, whereas the root attitudes of wholesomeness are generosity, kindness, and wisdom. Expressions of these root qualities of wholesomeness are the four so-called immeasurables: kindness, equanimity, compassion, and appreciative joy (i.e., joy that goes beyond mere self-satisfaction, including joy for the good fortune of others). Cultivation of these qualities is seen as a primary antidote to unwholesome conduct and thoughts. Thus, the Buddhist ethic is a set of principles, motivations, and attitudes that guide and train us to orient toward what behavior helps or harms other creatures and our environment.

According to Buddhist understanding of human nature, unwholesome thoughts and actions arise from ignorance of the fundamental properties of existence (Bodhi, 2013), perhaps most fundamentally, the impermanence of all things. An intentional and concerted effort to supplant greed, aversion, and delusion by means of contemplative investigation (in which mindful awareness plays a central role) and wholesome behavior is seen to lead to wisdom and peace. Thus, the practice of mindfulness is central to this process, as is the supplanting of unwholesome attitudes by attitudes including generosity, kindness, equanimity, compassion, and appreciative joy.

This ethical system may seem well based in a rational, nontheistic set of values, but the question may arise: what are the practical steps that Buddhist psychological principles suggest to achieve wisdom and eliminate - or, more realistically, reduce - our tendency toward unwholesome attitudes and conduct? And how does mindfulness intersect with this pursuit, so that the very practice of mindfulness may be characterized as an embodied ethical act? Perhaps, a quote by a well-known nineteenth century mathematician and philosopher of ethics (with no apparent knowledge of, nor interest, in Buddhism) may be helpful here: "By Ethics I mean the doctrine of a special kind of pleasure or displeasure which is felt by the human mind in contemplating certain courses of conduct, whereby they are felt to be right or wrong, and of a special desire to do the right things and avoid the wrong ones" (Clifford, 1879, p. 106). This quotation suggests a relationship between the contemplation of certain courses of conduct and their hedonic and anhedonic effects upon the mind (within the body). Such an idea may provide clues toward the direction in which this discussion is going.

To review the major characteristics of mindfulness practice, as outlined in numerous modern Theravada Buddhist texts aimed at a Western audience as well as consistent with the definition of mindfulness that is central to mindfulness-based interventions (e.g., mindfulness-based cognitive therapy) adapted from mindfulness-based stress reduction (KabatZinn, 2013), there are at least six essential qualities of mindfulness that consistently come up in Buddhist writings, some emphasized by individual authors more than others (e.g., Bodhi, 1984; Gunaratana, 2001; Goldstein, 2002; KabatZinn, 2013): (a) Deliberate intention to pay attention to momentary experience; (b) Clear focus on aspects of active, unprejudiced investigation of moment-to-moment experience; (c) Continuity of a precise moment-to-moment awareness of immediate experience; (d) Assumption of importance of both the training of mindfulness and its gradual acquisition; (e) A marked distinction from typical, everyday modes of consciousness; and (f) Inherent interdependency, or melding, of immediate awareness with attitudes of openness, acceptance, kindness, curiosity, and patience toward perceived experience (underpinnings of "non-judgmentalness").

Those latter attitudes thus underlie the special kind of mental awareness called mindfulness and are, in fact, necessary to make it possible for us to volitionally attend to ongoing experience in a continuous, unprejudiced manner: attention to experience is never emotionally neutral or devoid of attitudes toward what we are observing in any situation. Whether the object of attention is of intimate, social, or professional nature, we enter into all encounters, consciously or unconsciously, with certain attitudes and emotions - perhaps a sense of confidence, anxiety, openness, or desire for control, just to name a few. This pertains to any task or event, simple or complex: we may be curious, interested, enthusiastic, bored or irritated, even before we begin to place attention or absorb ourselves in a situation. These attitudes and emotions are bound to color our perceptions, in terms of how and what we attend to under specific circumstances, so that attitudes and emotions, on the one hand, and parameters of attention, on the other, are reciprocally affected by each other. Our attitudes and affect influence our ability to pay attention, and the way we pay attention will affect our attitudes and emotions. An agitated state of mind, for example, is simply not conducive to paying seamless attention to what is occurring, and is likely to contribute to partial or distorted assessments of what transpires. A person negatively biased to a certain situation is likely to be occupied 
with proliferation of judgments about the circumstance she finds herself in. A calm, patient, and open person will likely have more resources to maintain an unbiased perception of ongoing stimuli and events than someone who is aversively prone. While this may seem quite obvious, existing experimental psychological literature on attentional phenomena all but ignores this fact.

The meditative practice of intentionally turning awareness to moment-to-moment experience is also subject to this same principle, whatever the object of our awareness may be, whether a physical sensation, like the breath, or complex objects, like thoughts or mood states. Perhaps, for example, we attempt to attend to the in-breath and the out-breath and notice a sense of constriction in our chest. In typical habitual states of mind, we are often quick to make judgments, begin to analyze and evaluate our immediate experience, get caught up with thoughts related to the discomfort or emotions that the attentional focus brings, and thus literally lose touch with the ongoing perception of breathing itself. The breath is uncomfortable, and our minds reel on about the discomfort and unpleasantness we feel. In so doing, we have lost touch with mindful awareness of the breath, our state of comfort is not enhanced, and we may actually start to feel more distressed by the awareness of labored breathing.

On the other hand, imagine we can somehow even occasionally, for say a few seconds or minutes, supplant the judging mind with an attitude of kindness, curiosity, generosity and patience toward these sensations, which already exist and which we may not be able immediately to change. We might even be able to generate a subtle feeling of compassion toward this unstoppable unpleasant process that is unfolding within our own bodies, as well as the courage to stay tuned in to this unpleasant experience for the moment. My own experience, as well as those of many others, has it that such an attitudinal stance can make an enormous difference for our awareness of the moment. Awareness of the moment becomes more stable and refined. The breath may or may not become more comfortable, but the benevolent orientation toward to the uncomfortable sensations often also transforms our experience of it in a more eudemonic, soothing, and curious, investigative direction. We may also find that, as we can stay in closer contact with the tightness of the chest, we, perhaps, begin to notice how this sense of constriction changes from phase to phase of breathing; we may also develop insightswithout analysis - of the emotional state connected to the current state of discomfort. Under the best of circumstances, we might also realize that certain mental or physical factors serve to maintain the tightness, and we become able to do something about them.

This benevolent stance toward our experience reflects, in my opinion, an internally consistent ethical value system aimed not only to one's own perceptions and thoughts but also to all objects of perception and thought. In fact, even one's own processes become impersonal as objects of awareness; our own experience, to which we turn with openness, is then just one focus of attention and not so tied up with a sense of "me-ness." The more personal aspect becomes an identification with the ethical virtues and conduct of a particular openhearted perspective to all aspects of experience.

To be clear, such a stance in no way represents any kind of fatalistic approach. To the contrary, judgments are natural consequences of this ethical stance that will guide and motivate our actions. However, they are judgments and evaluations that are informed by a less prejudiced, or biased, perspective than often the case. As Olendzki (2011), p. 61, has written, "mindful attention neither favors nor opposes the object, but rather expresses the quality of equanimity. This is where modern definitions of mindfulness get the sense of not judging the object but of accepting it just as it is." Thus, ethical judgments are exacted, but they are made from a place of composure, clarity, and benevolent unconditionality.

\section{The Embodied Aspect of Ethics in Mindfulness Practice}

It is all well and good to note the importance of such ethical attitudinal qualities as kindness, equanimity, generosity, compassion, patience, acceptance, and courage. These virtuous characteristics, of course, play a significant role in all the world's major religions, but typically, as previously mentioned, have a morally prescriptive nature. Obviously, however, these attitudes cannot be mandated, and we are often left with the feeling that we might like to cultivate and nurture them in our lives, but have little idea of how to achieve this. In Buddhist practice, procedures exist explicitly aimed at enhancing these qualities like loving-kindness and compassion meditations (Hofmann et al., 2011; Salzberg, 2011). However, mindfulness practice, in itself, also serves as an invitation to entertain these qualities, as well as we can at any point in time, and to examine how their presence - and absence - influence our basic sense of moment-to-moment awareness. Thus, there is an emphasis upon a personally experienced process, in which we examine how our awareness is influenced by "trying out" the possibility of eliciting kindness, openness, and patience toward immediate experience, be the experience pleasant, unpleasant, or neutral. There is no moral imperative or expectation of success, just a gentle invitation to give it a try. In other words, it is a kind of open-ended investigation of what occurs within our perceptible experience when we attempt to be kind and accepting to mental content that unfolds from moment to moment, paradoxically even allowing the failure to achieve these states to be part of the process (i.e., accepting the fact that we may not be able to feel any sense of kindness at the moment may, nevertheless, still reinforce the process!). This practice is often supported by verbal priming of the meditation instructions with words and phrases 
emphasizing "letting go," "gently returning to the object of attention after a phase of distraction," assuming a benevolent stance "as well as one can at the moment." And the process is also likely to be strengthened when the mindfulness teacher seems genuinely to embody the qualities she employs in her instructions.

Corresponding to Clifford's (1879), p. 106, notion that the mind may experience "a kind of pleasure or displeasure when contemplating certain courses of conduct," experienced mindfulness meditators and participants in mindfulness-based programs often acknowledge experiencing a sense of contentment and wellbeing (eudemonia) as a consequence of mindfulness practice, sometimes even under very challenging conditions of life. For example, after completing an 8week mindfulness-based intervention, a patient with multiple sclerosis wrote:

"When I came home yesterday [from a mindfulness class], I received the news that Davis, the grandchild of my best friend had just died. He was only 8 months old and had leukemia. In such moments, I've always screamed from within and my feelings have consumed me like a Tsunami. Yesterday, this didn't happen. The healing calm of the day of practice helped me, and I could use all my mindfulness to be with both Davis and myself through this transition .... . Never before in my life have I experienced such a deep sense of peace, as I often do when I can pay attention to being mindful."

Such reports suggest that cultivation of mindfulness may be more about repeatedly coming into contact with those, perhaps merely brief, moments when our awareness is inhabited by peace, calm, and acceptance, than it is about learning merely to be more attentive to moment-to-moment experience. Indeed, studies often reveal very modest benefits on attentional effects upon even very long-term meditators (e.g., Daubenmier et al., 2013), and it is seems implausible that an 8-week mindfulness-based cognitive therapy or stress reduction will have pronounced effects upon our abilities to pay attention. On the other hand, there are preliminary indications that development of attitudes like compassion may mediate the beneficial effects of mindfulness upon psychosocial benefits in clinical studies of mindfulness-based interventions (Kuyken et al., 2010).

This central aspect of mindfulness, then, represents an embodied experience of a feeling of wellbeing that is not fully contingent upon, nor fully conditioned by, the circumstances in which we find ourselves. The sense of calm, ephemeral as it may be, comes to be known to us as more likely to occur when we attempt a kind and compassionate stance toward our immediate situation. It is embodied because it is no abstraction: we feel it in our bodies and our minds. A spectrum of integrally related ethical qualities - kindness, compassion, equanimity, tolerance, generosity, courage, just to name a few-becomes associated with the physical and mental perception of a special state of eudemonia, which for many people may have never or only rarely experienced before. Always reliable it may not be, but we develop a certain trust, based upon regular practice, that the likelihood that this equanimous type of awareness may arise is much greater when we attempt, on purpose, to approach each moment with tolerance, courage, and acceptance.

This habit is not meant only for daily sessions of formal meditation exercises. Formal meditation only allows a more controlled environment, for a practice ultimately aimed at informing and generalizing to our everyday lives. Ideally, the way we live our lives - in terms of what we do for a living, how we communicate with and treat others, how we interact with nature - all come to be a reflections of the ethical stance we attempt to cultivate by the practice of mindfulness. Of course, none of these factors operate independently of the others, and the very ambitious goal is that they be mutually reinforcing.

In conclusion, I have briefly tried to describe mindfulness as an act of an embodied ethic, inherently woven into the fabric of the Buddhist system of ethical conduct and virtue (Sila from the Pali). This understanding tangibly fuses cognitive dimensions (e.g., of attention, memory, and consciousness) together with ethical qualities (e.g., compassion, kindness, courage, and equanimity). It represents a radical deviation from Western academic psychology's relatively isolated treatment of cognition and its almost complete neglect of the influence of ethical values upon psychological and cognitive functioning. This analysis also indicates that any attempt to fathom the Buddhist notion of mindfulness cannot be made within the tight contours of a cognitive model of attention and meta-cognition but requires a much broader contextual, perhaps even constitutive, framework. Perhaps, a greater focus upon these relationships may contribute to a deeper comprehension of the nature of mind and existence.

\section{References}

Bodhi, B. (1984). The noble eightfold path: way to the end of suffering. Pariyatti (Sri Lanka): Buddhist Publication Society. Available online: http://www.accesstoinsight.org/lib/authors/bodhi/waytoend.html

Bodhi, B. (2013). Nourishing the roots: essays on Buddhist ethics. In Access to Insight (Legacy Edition, first published 15). http://www. accesstoinsight.org/lib/bodhi/wheel259.html .

Clifford, W. K. (1879). On the scientific basis of morals. London: Macmillan.

Daubenmier, J., Sze, J., Kerr, C. E., Kemeny, M. E., \& Mehling, W. (2013). Follow your breath: respiratory interoceptive accuracy in experienced meditators. Psychophysiology, 50, 777-789.

Germano, D. (2014). Contemplation in contexts: Tibetan Buddhist meditation across the boundaries of the humanities and sciences. Paper 
presented at the International Symposium for Contemplative Studies, Boston, November 1, 2014

Goldstein, J. (2002). One dharma: the emerging Western Buddhism. New York: HarperCollins.

Grossman, P. (2011). Defining mindfulness by how poorly I think I pay attention during everyday awareness and other intractable problems for psychology's (re) invention of mindfulness: comment on Brown et al. (2011). Psychological Assessment, 23, 1034-1040.

Grossman, P., \& Van Dam, N. T. (2011). Mindfulness, by any other name...: trials and tribulations of sati in western psychology and science. Contemporary Buddhism, 12, 219-239.

Gunaratana, B. (2001). Mindfulness in plain English. Summerville: Wisdom.

Hofmann, S. G., Grossman, P., \& Hinton, D. E. (2011). Loving-kindness and compassion meditation: potential for psychological interventions. Clinical Psychology Review, 31, 1126-1132.
Kabat-Zinn, J. (2013). Full catastrophe living: using the wisdom of your body and mind to face stress, pain and illness. New York: Bantam Books.

Kuyken, W., Watkins, E., Holden, E., White, K., Taylor, R. S., Byford, S., Evans, A., Radford, S., Teasdale, J. D., \& Dalgleish, T. (2010). How does mindfulness-based cognitive therapy work? Behavior Research and Therapy, 48, 1105-1112.

Langer, E. J., \& Newman, H. M. (1979). The role of mindlessness in a typical social psychological experiment. Personality and Social Psychology Bulletin, 5, 295-298.

Monteiro, L., Musten, R., \& Compson, J. (2015). Traditional and contemporary mindfulness: finding the middle path in the tangle of concerns. Mindfulness, 6, 1-13.

Olendzki, A. (2011). The construction of mindfulness. Contemporary Buddhism, 12, 55-70.

Salzberg, S. (2011). Mindfulness and loving-kindness. Contemporary Buddhism, 12, 177-182. 